\title{
Multicolored Polyanilines Doped by Different Acid Dyes and Their Electrochromic Property
}

\author{
Xin $\mathrm{Li}^{\mathrm{a}}$, Yiping Zheng ${ }^{\mathrm{b}^{*}}$ and Congju $\mathrm{Li}^{\mathrm{c}}$ \\ Beijing Key Laboratory of Clothing Materials R\&D and Assessment, School of Materials Science \& \\ Engineering, Beijing Institute of Fashion Technology, Beijing 100029,P. R. China \\ aclylx@bift.edu.cn, ${ }^{b}$ libzyp@bift.edu.cn, ${ }^{c}$ clycongjuli@bift.edu.cn
}

\begin{abstract}
Multicolored polyanilines (PANIs) are synthesized by using different acid dyes containing sulfonic acid group as the functional dopant. It is found that the FTIR spectra of the acid dye doped PANI and pure PANI are similar with each other, which are all doped state PANI, and the new arising peaks indicate the acid dyes existing in the PANI molecular. The UV-Visible spectra show that the different acid dye doped PANI present different colors as the effect of the chromophore of the acid dye. From the $\mathrm{CV}$ curves, it is clear that all the acid dye doped PANIs exist two pairs of oxidation and reduction peaks with vivid reversibly multicolor changes from light color $(-0.5 \sim 0 \mathrm{~V})$ to dark color $(0 \sim 0.8 \mathrm{~V})$. It is shown that acid dye doping is an effective method to broaden the color change range of the electrochromic mateials.
\end{abstract}

Keywords: PANI, Functional doping, Acid dye, Multicolore, Electrochromism

\section{Introduction}

As a kind of electrochromic material (ECM), conducting polymer has become one of the most important fields in functional material science due to its highly controlled conjugated molecular structure, flexible mechanical property, rapid response, excellent coloration efficiency and long life and many other specialties, which can be used widely in large-area display[1,2], storage devices[3], military camouflage[4], smart windows[5], anti-glare mirrors for cars[6] and so on. Among those conducting polymers, polyaniline (PANI) have attracted more and more attentions because of their adjustable conductivity from insulating to conducting range by a reversible doping and de-doping process[7]. By functional doping, PANI can obtain many special characteristics, such as solubility[8], photoisomerization[9], chirality[10] and hydrophobicity[11] etc. The most frequently used dopant including polystyrene sulfonic acid (PSS)[12,13], dodecylbenzenesulfonic acid (DBSA)[14], p-toluenesulfonic acid (PTSA)[15], camphor sulfonic acid (CSA)[16] and fluoro-containing-alkyl acid[11] and so on. Acid dye is an important kind of dye with

*Corresponding author: libzyp@bift.edu.cn 
complete chromatogram and bright in color. The structures of the acid dye mostly are aromatic sulfonic acid sodium salt, and the chromophores are mainly azo and anthraquinone. Based on the special doping mechanism of conducting polymer, the acid dyes can act as dopant to tune their color states and EC properties. Compare with the structure modification (substituent[17] and graft[18]), the acid dye doping is simple with high controllability. But only few studies are found by now. In 1998, Emerson M and co-workers[19] studied the effect of this organic dye indigo carmine dopant on the electrochromic properties of polypyrrole (PPy) and polypyrrole/ dodecylsulfate (PPy/DS) films. They found that introducing the indigo carmine into the PPy and PPy/DS films can shorten the response time, increase the stablility and chromatic contrast.

In this paper, different acid dyes are used as the functional dopants to prepare multicolored PANIs by chemical oxidation method. The resulted PANIs present multicolors and can switch between light color and dark color. The paper proposed a method to enrich the color range of electrochromic mateials.

\section{Experimental}

\subsection{Materials}

Aniline (An, A.R., Tianjing Guangfu Fine Chemical Research Institute) was distilled under reduced pressure. All other reagents, such as Ammonium persulfate (APS, $\left(\mathrm{NH}_{4}\right)_{2} \mathrm{~S}_{2} \mathrm{O}_{8}, A$. R., Beijing Yili Fine Chem. Co.), ethanol (A.R., Beijing Chemical Plant), ether (A.R., Beijing Chemical Plant), dimethyl sulfoxide (DMSO, A.R., Tianjing Guangfu Fine Chemical Research Institute), HCl(A.R., Beijing Chemical Plant), acid red G(ARG, C.R., Qingdao Chuanlin dye industry co., LTD ), acid orange II (AOII, C.R., Qingdao Chuanlin dye industry co., LTD), weak acid brilliant blue RAWL (RAWL, C.R., Shandong Double Dragon Chemical Co., Ltd.), acid red B (ARB, C.R., Tianjin Sanhuan Chemical Co., Ltd.) and acid light yellow G(ALYG, C.R., Qingdao Chuanlin dye industry co., LTD) were used as received without further treatment. The water used in the experimental is and distilled water. Table 1 gives the molecular structures of five different acid dyes.

Table 1. The Molecular Structure, Conductivity And Color Of Different Acid-Dye Doped Pani

\begin{tabular}{lccc}
\hline Molecular structure of acid dye & Resulted PANI & $\begin{array}{c}\text { Conductivity } \\
(\mathrm{S} / \mathrm{cm})\end{array}$ & $\begin{array}{c}\text { Color of } \\
\text { solid }\end{array}$ \\
\hline ARG & dark red & 0.15 & PANI-ARG \\
\hline
\end{tabular}

PANI-AOII black


RAWL<smiles>Cc1cc(C)c(S(=O)(=O)O[Na])c(C)c1Nc1ccc(Nc2c(C)cc(C)c(S(=O)(=O)O[Na])c2C)c2c1C(=O)c1ccccc1C2=O</smiles>

PANI-RAWL

0.92

dark blue

ARB

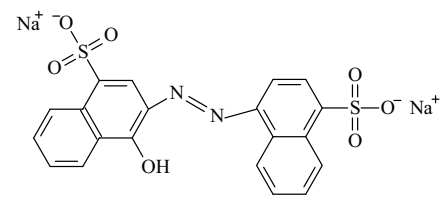

PANI-ARB

0.85

dark brown

ALYG

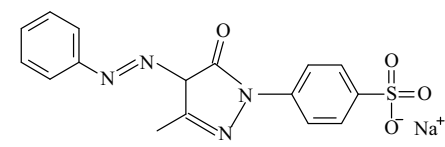

PANI-ALYG

0.14

dark yellow

\subsection{In-situ Polymerization}

$1 \mathrm{mmol} \mathrm{ARG}$ was put into $25 \mathrm{~mL} \mathrm{HCl}$ solution $(0.08 \mathrm{~mol} / \mathrm{L})$ under magnetic stirring to forming the homogeneous solution. Then, added $3 \mathrm{mmol}$ APS and $2.5 \mathrm{mmol}$ An into the solution and kept stirring for $24 \mathrm{~h}$ under $0-10^{\circ} \mathrm{C}$. The product was collected via filtration, washed with de-ionized water, ethanol and ether for several times, and then dried at $40-60^{\circ} \mathrm{C}$ under vacuum for $6 \mathrm{~h}$ to obtain a dark-red powder. The resulted product was called PANI-ARG. The molar ratio of An: APS: ARG was 1: 1.2: 0.4.

The other acid dye doped PANI including PANI-AOII, PANI-RAWL, PANI-ARB and PANI-ALYG were prepared in a parallel method with the same molar ratio of An: APS: acid dye $=1: 1.2: 0.4$. The conductivity and color of different acid-dye doped PANI are listed in Table 1. Pure PANI was synthesized at the parallel conditions without added acid dye as a comparison sample, the color of the resulted PANI is dark green with the conductivity of $0.08 \mathrm{~S} / \mathrm{cm}$.

\subsection{Measurements}

The structure of the products was characterized by FTIR spectra ( Nicolet, Nexus 670, ) and UV-Vis spectra (Perkin Elmer, Lambda 750). The electrical conductivities of the samples were measured by four-probe conductivity meter (Keithley 6221 + 2182A, Keithley Instruments Inc.) at room temperature and humidity of $40 \%$ R.H. The cycle voltammogram measurement was recorded in an electrolyte solution containing $0.1 \mathrm{M} \mathrm{HCl}$ on a Zahner IM6 workstation. The three-electrode system was used with the ITO glass coating with acid dye doped PANI (DMSO as the solvent) as the working electrode, and the counter and reference electrodes were platinum and standard calomel electrode (SCE), respectively. 


\section{Results and Discussion}

\subsection{FTIR spectrum}

Five different acid dyes containing sulfonic acid group including ARG, AOII, RAWL, ARB and ALYG were used as function dopant to prepare PANI. The FTIR spectra of the five different acid dye doped PANIs are given in Fig.1. From Fig.1, it is clear that the five spectra are similar with each other, the shape and position of the main absorption peaks are all similar, which are all doped state PANI[20]. For example, the $\mathrm{C}=\mathrm{C}$ stretching deformation of the quinoid at $1570 \mathrm{~cm}^{-1}$ and benzenoid rings at $1500 \mathrm{~cm}^{-1}$, the C-N stretching of the secondary aromatic amine at $1300 \mathrm{~cm}^{-1}$, the aromatic C-H in plane bending at $1142 \mathrm{~cm}^{-1}$, the out-of-plane deformation of $\mathrm{C}-\mathrm{H}$ in the 1,4-disubstituted benzene ring at $815 \mathrm{~cm}^{-1}$ and bending vibration of $\mathrm{N}-\mathrm{H}$ at $666 \mathrm{~cm}^{-1}$ are all quite distinct in acid dye doped PANI. Besides, the bands at $3446 \mathrm{~cm}^{-1}$ and $3232 \mathrm{~cm}^{-1}$, attributed to the $\mathrm{N}-\mathrm{H}$ and $=\mathrm{NH}$ stretching mode respectively, are also observed. However, the band at $1034 \mathrm{~cm}^{-1}$ assigned to the stretching vibration of $\mathrm{S}=\mathrm{O}$ of sulfonic acid group, and two bands at $704 \mathrm{~cm}^{-1}$ and $603 \mathrm{~cm}^{-1}$ attributed to the stretching vibration of C-S and S-O respectively, are appeared only for acid dye doped PANI, which is different from the pure PANI[7] and indicating the molecules of acid dye have existed in PANI molecules.

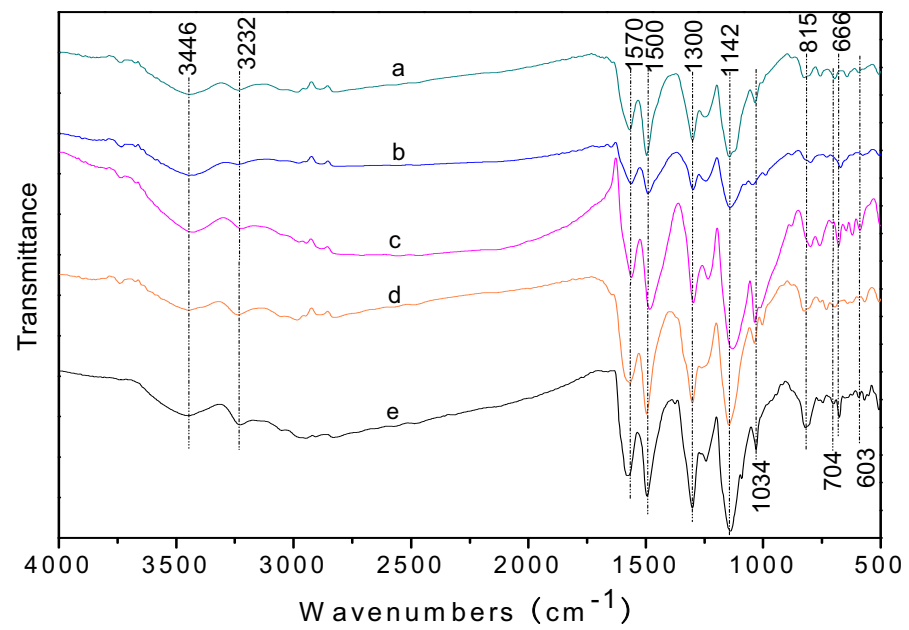

Fig. 1 FTIR spectra of different acid dye doped PANI

(a) PANI-ARG; (b) PANI-AOII; (c) PANI-RAWL; (d) PANI-ARB; (e) PANI-ALYG

\subsection{UV-Visible Spectrum}

From Table 1, we know that acid dye doped PANIs all have good electric conductivity with the same magnitude varying from $0.14 \sim 0.92 \mathrm{~S} / \mathrm{cm}$. Among them, PANI-RAWL and PANI-ARB have higher conductivities compared with PANI-ARG, PANI-AOII and PANI-ALYG, which may due to the two sulfonic acid groups in the molecules of RAWL and ARB resulting higher doping level of PANI. Besides, the resulted acid dye doped PANIs solid particles have different colors varying from dark red, black, dark blue, dark brown to dark yellow, which is different from the dark green of pure PANI. This point has also been proved by their UV-Visible spectra as shown in Fig. 2. For pure PANI (Fig. 2f), there have two bands at $338 \mathrm{~nm}$ and $446 \mathrm{~nm}$ (assigned as the $\pi-\pi^{*}$ and $n-\pi^{*}$ transition respectively) and 
with a long tail centered at $640 \mathrm{~nm}$ (assigned as the delocalized polaron band)[7], indicating the PANI belong to the conducting state of PANI. Compared with the pure PANI, the spectra of acid dye doped PANIs appear some red shifts. This is because that the doping of organic sulfonic acid group will affect the molecular configuration of PANI and consequently influencing its band structure, resulting in the variation of optical property. When the big size counter anion doping PANI, it will decrease the intermolecular interaction of PANI resulting in an extended conformation of PANI, thus is better for the charge delocalization and decreasing the electronic transition energy gap, so as to arise red shift. Moreover, the a, b, c, $\mathrm{d}$ and e spectra present varying strength and width of polaron absorption peak due to the acid dye doping. At the same time, from Fig. 2, the basic color of the pure PANI and acid dye doped PANI can also be observed. For example, the absorption peak at 510-540nm of PANI-ARG (Fig. 2a) matched the wine color of the matter, the peak centered at $460 \mathrm{~nm}$ of PANI-AOII (Fig. 2b) matched orange of the matter. Besides, for 590-630nm of PANI-RAWL (Fig. 2c), the color is green-blue; for 530nm of PANI-ARB (Fig. 2d), the color is purple; for $405 \mathrm{~nm}$ of PANI-ALYG, the color is yellow-green; for 640nm of pure PANI, the color is green. This indicates that the color of PANI after doped by acid dye has changed as the effect of the chromophore of the acid dye, which consequently presents multicolor.

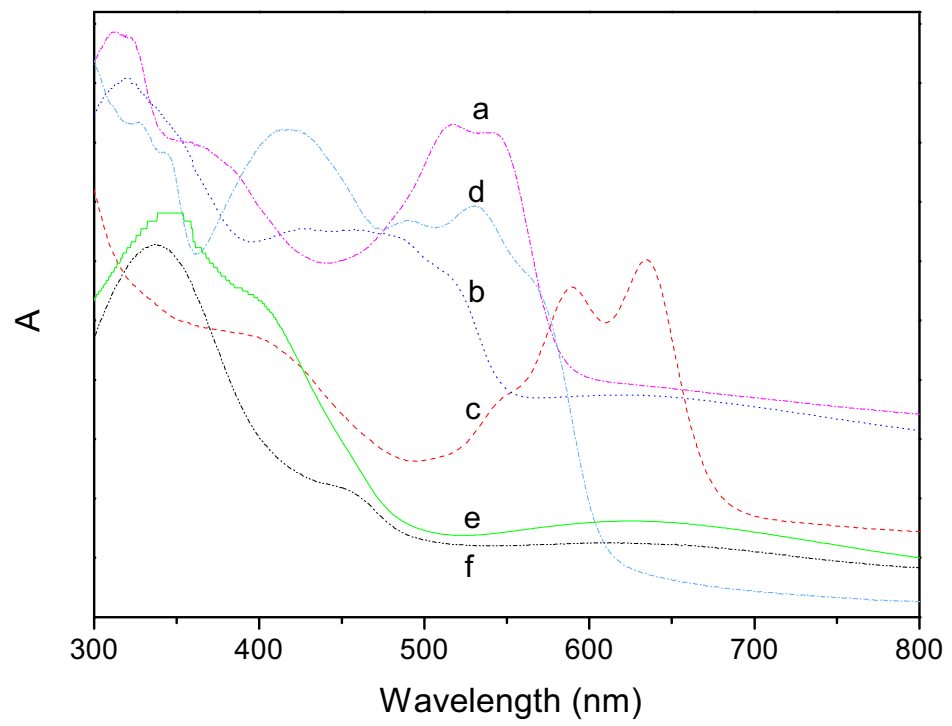

Fig. 2 UV-Visible spectra of pure PANI and different acid dye doped PANI (a) PANI-ARG; (b) PANI-AOII; (c) PANI-RAWL; (d) PANI-ARB; (e) PANI-ALYG; (f) pure PANI 


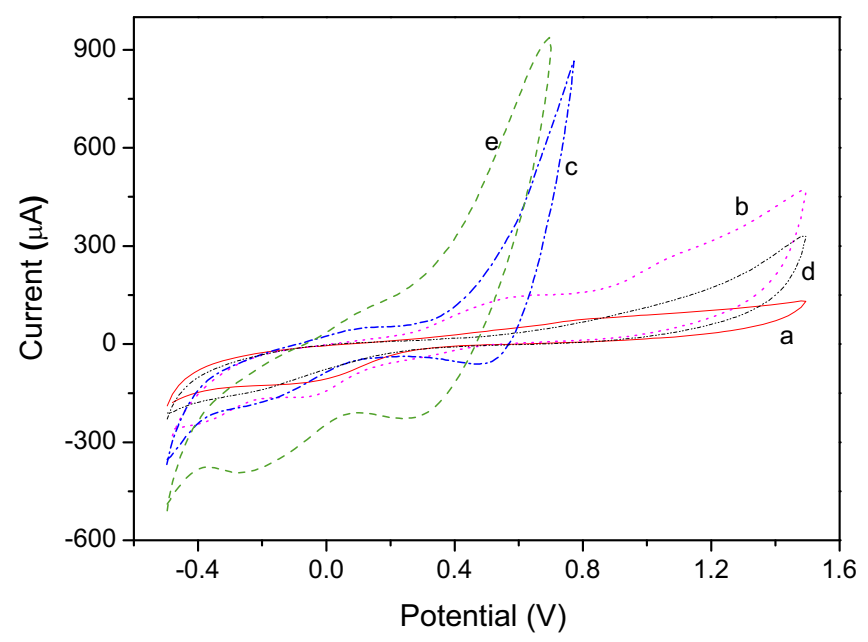

Fig. 3 CVs of different acid dye doped PANI

(a) PANI-ARG; (b) PANI-AOII; (c) PANI-RAWL; (d) PANI-ARB; (e) PANI-ALYG

\subsection{Electrochromic Property}

The successive cycle voltammograms (CVs) of acid dye doped PANIs are shown in Fig. 3. It is can be observed that for all acid dye doped PANIs, there exist two oxidation peaks and two reduction peaks. For CV of PANI-ALYG, the oxidation current is the maximum with the value of $800 \mu \mathrm{A}$ indicating a stronger redox reaction, and there are two obvious reduction peaks centered at $-0.26 \mathrm{~V}$ and $+0.28 \mathrm{~V}$, respectively. The CV of PANI-RAWL is similar with that of PANI-ALYG, but the others have relative gentle curves with smaller redox current and obscure redox peaks. However, all five acid dye doped PANIs have distinct color changes when the voltage varied. Fig. 4 gives $\mathrm{CV}$ and color change of PANI-RAWL. As seen from Fig.4, PANI-RAWL presents light blue at $-0.5 \sim 0 \mathrm{~V}$ and dark blue at $0 \sim 0.8 \mathrm{~V}$, respectively. The color changes of acid dye doped PANIs and pure PANI are given in Fig. 5. It is clear that the acid dye doped PANIs take on different color variation, and their color is vivid. Besides, they all present light colors at $-0.5 \sim 0 \mathrm{~V}$ and dark colors at $0 \sim 0.8 \mathrm{~V}$. This indicates that acid dye doping is an effective method to broaden the color change range of the electrochromic mateials.

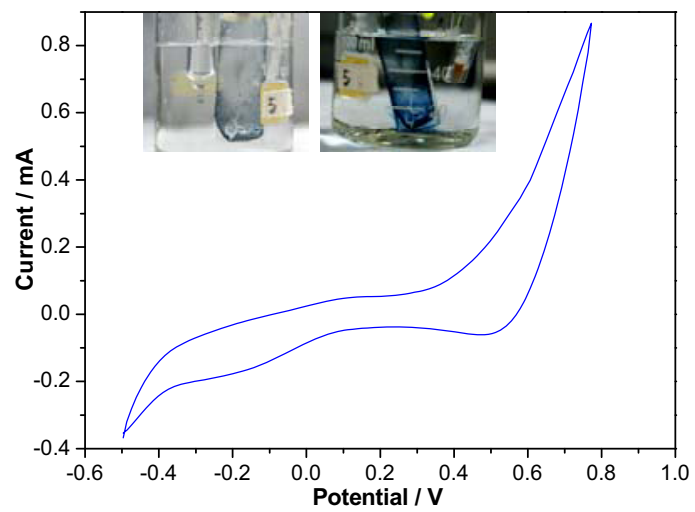

Fig. $4 \mathrm{CV}$ and color change of PANI-RAWL (-0.5 0V): light blue; $(0 \sim 0.8 \mathrm{~V})$ : dark blue 


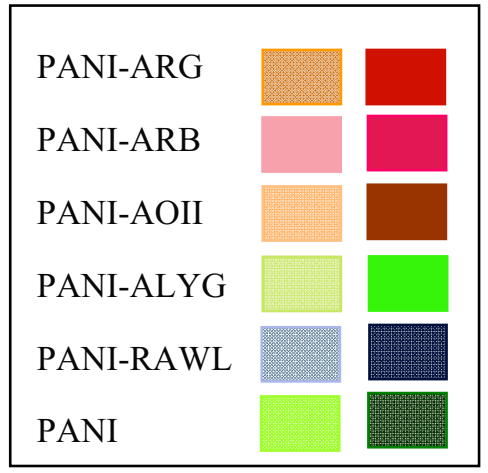

Fig.5 Color changes at different voltage of acid dye doped PANIs and pure PANI (-0.5 0V): light color; $(0 \sim 0.8 \mathrm{~V})$ : dark color

\section{Summary}

Multicolored PANIs doped by different acid dyes are prepared by chemical oxidation. The results show that the acid dye doped PANI and pure PANI are all doped state PANI with the conductivity in the range of $0.14 \sim 0.92 \mathrm{~S} / \mathrm{cm}$. The structure characterization indicates that the acid dyes existing in the PANI molecular, and acid dye doped PANI present different colors as the effect of the chromophore of the acid dye. Moreover, there exist the oxidation and reduction peaks in the CV curves of acid dye doped PANIs, and all the acid dye doped PANIs show vivid color variation and present light colors at $-0.5 \sim 0 \mathrm{~V}$ and dark colors at $0 \sim 0.8 \mathrm{~V}$. This study provided an idea for enriching the color range of electrochromic mateials.

\section{Acknowledgements}

This project was financially supported by The National Nature Sciences Foundation of China (No. 20974005), Beijing Nova Programme (No. 2007B010), Scientific and Technology Key Project of Beijing Educational Committee (No. KZ201410012017), and Training Program of the Scientific Research Promotion Plan of Beijing Institute of Fashion Technology (No. 2014AL-04).

\section{References}

1. H. Pagès, P. Topart, D. Lemordant, Wide band electrochromic displays based on thin conducting polymer films, Electrochimica Acta 46 (2001) 2137-2143.

2. P. Somani, A. B. Mandale, S. Radhakrishnan, Study and development of conducting polymer-based electrochromic display devices, Acta Materialia 48 (2000) 2859-2871.

3. G. Nyström, M. Strømme, M. Sjödin, L, Nyholm, Rapid potential step charging of paper-based polypyrrole energy storage devices, Electrochimica Acta 70 (2012) 91-97.

4. X. Li, G. L. Zhao, J. Qian, Zh. Y. Fu. Preparation, structure and electrochromic properties of poly(3,4-ethylenedioxythiophene) based conducting textile, Chemical Journal of Chinese Universities 30 (2009) 1052-1054.

5. V. Seshadri, J. Padilla, H. Bircan, B. Radmard, R. Draper, M. Wood, T. F. Otero, G. A. Sotzing, Optimization, preparation, and electrical short evaluation for $30 \mathrm{~cm} 2$ active 
area dual conjugated polymer electrochromic windows, Organic Electronics 8 (2007) 367-381.

6. K.Y. Shen, C. W. Hu, L. Ch. Chang, K. Ch. Ho, A complementary electrochromic device based on carbon nanotubes/conducting polymers, Solar Energy Materials and Solar Cells 98 (2012) 294-299.

7. X. Li, M. X. Wan, X. N. Li, G. L Zhao. The role of DNA in PANI-DNA hybrid: template and dopant, Polymer 50 (2009) 4529-4534.

8. G. S. Braga, L. G. Paterno, J. P. H. Lima, F. J. Fonseca, A. M. de Andrade, Influence of the deposition parameters on the morphology and electrical conductivity of PANI/PSS self-assembled films, Materials Science and Engineering: C 28 (2008) 555-562

9. H. Y. Huang, J. W. Jian, Y. T. Lee, Y. T. Li, T. Ch. Huang, J. H. Chang, L. Ch. Yeh, J. M. Yeh, Effect of photoisomerization on the electroactivity and electrochromic behavior of aniline pentamer-based polymers with azo chromophore as reversibly switchable pendant group, Polymer 53 (2012) 4967-4976.

10. Y. Li, B. Ch. Wang, W. Feng, Chiral polyaniline with flaky, spherical and urchin-like morphologies synthesized in the L-phenylalanine saturated solutions, Synthetic Metals 159 (2009) 1597-1602.

11. J. P. Jin, X. Li, D. Q. Zhang, L. Zhao. The doping/de-doping process induced polyaniline conductive textile wettability switching. Acta Polymerica Sinica 2 (2010) 192-198.

12. C. P. L. Rubinger, L. C. Costa, R. Faez, C. R. Martins, R. M. Rubinger, Hopping conduction on PANI/PSS blends, Synthetic Metals 159 (2009) 523-527.

13. J. Wei, Sh. X. Xiong, Y. Bai, P.T. Jia, J. Ma, X. H.Lu, Polyaniline nanoparticles doped with star-like poly(styrene sulfonate): Synthesis and electrochromic properties, Solar Energy Materials and Solar Cells $\underline{99}$ (2012), 141-147.

14. S. Bilal, S. Gul, K. Ali, A. Ali Shah, Synthesis and characterization of completely soluble and highly thermally stable PANI-DBSA salts, Synthetic Metals 162 (2012) 2259-2266.

A. B. da Silva, R. E.S. Bretas, Preparation and characterization of PA6/PAni-TSA nanofibers, Synthetic Metals 162 (2012) 1537-1545.

15. M. Bée, D. Djurado, J. Combet, M. Telling, P. Rannou, A. Pron, J. P. Travers, Dynamics of camphor sulfonic acid in polyaniline (PANI-CSA): a quasielastic neutron scattering study, Physica B: Condensed Matter 301(2001) 49-53.

16. M.C. Bernard, A. Hugot-Le Goff, S. Joiret, H. Arkoub, B. Saïdani, Influence of the nature of substituent on the charge mechanisms in substituted polyanilines (SPANI, POMA) studied by Raman and optical spectroscopies, Electrochimica Acta 50 (2005) 1615-1623.

17. M. Cabuk, M. Yavuz, H. I. Unal, Electrokinetic properties of biodegradable conducting polyaniline-graft-chitosan copolymer in aqueous and non-aqueous media, Colloids and Surfaces A: Physicochemical and Engineering Aspects 460 (2014) 494-501.

18. M. G. Emerson, M. A. De Paoli, Polypyrrole color modulation and electrochromic contrast enhancement by doping with a dye, Adv. Mater. 10 (1998) 790-793.

19. X. Li, J. Y. Shen, M. X. Wan, Zh. J. Chen, Y. Wei, Core-shell structured and electro-magnetic functionalized polyaniline. Synthetic Metals 6 (2007) 575-579. 